\title{
Can Ophthalmoscope Predict Silent Coronary Artery Disease in Patients with Type 2 Diabetes Mellitus?
}

\author{
Naglaa Abdul-Maboud Soliman1, Wafaa Mostafa Abd-El Gawad2* \\ ${ }^{1}$ Internal Medicine Department, Faculty of Medicine, Cairo University, Cairo, Egypt \\ ${ }^{2}$ Geriatrics and Gerontology Department, Faculty of Medicine, Ain Shams University, Cairo, Egypt \\ Email: *wafaager@hotmail.com
}

Received 16 August 2014; revised 20 September 2014; accepted 21 October 2014

Copyright (C) 2014 by authors and Scientific Research Publishing Inc.

This work is licensed under the Creative Commons Attribution International License (CC BY). http://creativecommons.org/licenses/by/4.0/

(c) (i) Open Access

\begin{abstract}
Background \& Aim: Diabetic retinopathy (DR) and Coronary Artery Disease (CAD) share similar pathophysiological background of vascular damage. So we aimed to study the relationship between DR and silent CAD in patients with type 2 diabetes mellitus (T2DM). Subject \& Methods: A cross sectional study was performed on 40 patients with T2DM from diabetic outpatient clinic in Ain Shams University Hospitals, Cairo, Egypt from June 2012 to December 2012. All patients were subjected to data collection, laboratory analysis and imaging studies. Patients with known CAD, abnormal resting or stress ECG, abnormal ejection fraction or segmental wall motion abnormalities, smoking history, hypertension, or abnormal lipid profile were excluded. Results: Mean age is $62.35 \pm 1.38$ years, $75 \%(n=30)$ were females, $75 \%(n=30)$ had $D R$, and $77.50 \%(n=31)$ had positive $\mathrm{Tc}^{99}$ scan. There is a significant positive association between $\operatorname{Tc}^{99} \mathrm{scan}$ and $\mathrm{DR}(\mathrm{p}$ value $=$ 0.029 ) as $86.7 \%$ of patients with DR had positive Tc $^{99}$ scan. Resting and stress perfusion TC $^{99}$ scan were significantly worse $(91.77 \%$ vs $100 \% ; 86.48 \%$ vs $96.27 \%$, p value $=0.008,0.005$ respectively) and microalbuminuria were significantly higher $(207 \pm 29.65$ vs $36 \pm 10.66 \mathrm{mg} / \mathrm{dl}$, p value $=<$ 0.001) in patients with DR. By binary logistic regression, DR was an independent predictor for CAD (OR was $16.377,95 \%$ CI was $1.017-263.586$, $p$ value $=0.049$ ) after adjustment of SBP and albuminuria. Conclusion: DR is an independent predictor of asymptomatic CAD even with normal stress ECG and echocardiography. Routine screening for CAD using $\mathrm{Tc}^{99}$ scan is recommended in patients with DR even if asymptomatic. More multi-centric prospective studies are needed to elucidate the effect of the degree of DR on CAD risk.
\end{abstract}

\section{Keywords}

Type 2 Diabetes Mellitus, Coronary Artery Disease, Diabetic Retinopathy, Tc ${ }^{99}$ Scan

\footnotetext{
"Corresponding author.
} 


\section{Introduction}

The importance of understanding the relationship between diabetic retinopathy (DR) and vascular disease is crucial for the physicians as the prevalence of diabetes continues to increase worldwide. Diabetic retinopathy is the commonest microvascular complication of diabetes. DR may start to develop as early as 7 years before the diagnosis of type 2 diabetes (T2DM) [1]. More than $60 \%$ of type 2 diabetic patients will have some degree of retinopathy after 20 years of onset of DM [1]. DM increases the risk of development of cardiovascular disease [2]. Current guidelines highlighted the importance of routine fundus examination for patients with T2DM which represent a unique opportunity for the clinician to visualize, assess and monitor the direct effects of diabetes on the microcirculation [3]. Recently, it was noted that DR may be one of the early signs of an increased risk of life-threatening systemic vascular complications [4] [5] like coronary artery disease (CAD) [6]. It has been noted that signs of DR could be a mirror to generalized microangiopathic processes that affect every organ in the body [4] [6] not only the eyes. Despite the widespread interest in studying the link between DR and CAD, the precise underlying pathophysiological mechanism is still uncertain [3].

The role of DR as a predictor for incident CAD is an interesting point of research as it allows both primary and secondary prevention of CAD through aggressive management of this complication. Till now, it is still unclear whether the presence of DR in Egyptian diabetic elderly patients is associated with silent CAD independent of other traditional cardiovascular factors like hypertension or smoking. Therefore, this study examined the association between the presence of DR and subclinical CAD using Single Photon Emission Computed Tomography (SPECT) in patients with T2DM in absence of other traditional risk factors and tested whether DR could act as a predictor for CAD or not.

\section{Subject and Method}

\subsection{Study Design and Setting}

A cross-sectional study was performed on patients with T2DM attending consequently to diabetic outpatient clinic in Ain Shams University Hospitals, Cairo, Egypt from June 2012 to December 2012.

For the purpose of the study, exclusion criteria were patients with a well-known history of cardiac disease including CAD, any abnormal echocardiography finding or abnormal resting or stress electrocardiograph; hypertension, elevated systolic blood pressure (SBP) $>130 \mathrm{mmHg}$ or diastolic blood pressure (DBP) $>80 \mathrm{mmHg}$, or on antihypertensive drugs. Also patients with acute or chronic kidney disease or abnormal creatinine, hyperlipidemia, or abnormal lipid profile or on lipid lowering agents; or past or current history of smoking or current urinary tract infections, cerebrovascular disease, peripheral artery disease were excluded. Moreover, patients who declined from participation during the study or refused to participate were also excluded. The study had been approved by the local ethical committees of Ain Shams University and all patients or their next kin provided informed consent to the work. Because of exclusion criteria of the study, only $10 \%(\mathrm{n}=40)$ of patients were eligible. $75 \%(n=300)$ of patients were excluded due to smoking, CAD, elevated blood pressure, elevated lipid profile, elevated serum creatinine and acute or chronic kidney disease. $15 \%(n=60)$ of patients were also excluded either due to refusal to participate, or withdrawal from the study.

\subsection{Data Collection}

All patients were subjected to data collection including personal characteristics, detailed medical history with especial focus on diabetes mellitus and its complications, and physical examination including standardized blood pressure measurement, screening for peripheral neuropathy using vibration sense perception examination and superficial pain sensation; and anthropometric assessment for weight, height, and body mass index (BMI).

\subsection{Fundus Examination}

Routine screening for diabetic retinopathy were done to all patients with T2DM as stated in the Clinical Practice Guidelines in the eye clinic by an experienced ophthalmologist specialized in retinal diseases using mydriatic indirect ophthalmoscopic examination and slit-lamp fundus examination with a precorneal lens. Diagnosis of DR was based on the International Clinical Diabetic Retinopathy Disease severity Scale [7] which depends on the presence of microaneurysms, intraretinal hemorrhage, venous beading, neovascularization, and vitreous/ preretinal hemorrhage [7]. 


\subsection{Cardiac Assessment}

Resting and stress Electrocardiograph were done to all participants to exclude patients with abnormal finding such as abnormal Q waves or deep T wave inversions, Left Bundle Branch Block, non-specific ST-T changes. 2 D Echocardiography was also done to exclude patients with segmental wall motion abnormalities, abnormal ejection fraction, or cardiac chamber dilation or hypertrophy. Nuclear cardiac imaging by Single Photon Emission Computed Tomography (SPECT) is a modality to assess myocardial perfusion especially in diabetics at risk of CAD. The presence of reversible defects in SPECT despite other normal cardiac tests is defined as silent CAD [8]. SPECT is the most commonly used and well-documented noninvasive method for diagnosis and risk stratification of coronary artery disease (CAD) [9]. It was evaluated by highly qualified nuclear medicine professors. It has good specificity $75 \%$ - 82\% [10] to assess myocardial ischemia. The specificity of SPECT scans can be improved up to $90 \%$ by using attenuation correction algorithms as well as incorporating the gated left ventricular ejection fraction and regional wall motion into test interpretations [11] which had been used in our study.

\subsection{Laboratory Investigations}

For each participant, 12 hours fasting blood sample was collected for fasting blood glucose, total cholesterol (TC), triglycerides (TG), high density lipoprotein-cholesterol (HDL-C), low density lipoprotein-cholesterol (LDL-C), glycosylated hemoglobin (HB A1c) and serum creatinine. Another $2 \mathrm{~h}$ postprandial blood sample was collected for glucose. For microalbuminuria, 24 hours urine samples collections were done to all participants to determine the urinary albumin excretion rate (UAER). All laboratory investigations were analyzed using standard laboratory techniques. Criteria of lipid profile values used for low risk DM without overt CAD were according to American diabetic association, 2011. Total cholesterol $<4 \mathrm{mmol} / \mathrm{L}$, LDL-C $<2.6 \mathrm{mmol} / \mathrm{L}$, HDL-C cholesterol $>1.0 \mathrm{mmol} / \mathrm{L}$ in males and $>1.3 \mathrm{mmol} / \mathrm{L}$ in females. Triglycerides $<1.7 \mathrm{mmol} / \mathrm{L}$. Serum creatinine $<$ $1.5 \mathrm{mg} / \mathrm{dl}(<132 \mu \mathrm{mol} / \mathrm{L})$.

\subsection{Statistical Analysis}

Data collected were revised, coded, tabulated and introduced into a personal computer. Qualitative data were presented in the form of number and percent. Quantitative data were presented in the form of means and SD. All data manipulation and analysis were performed using the 17th version of SPSS (Statistical Package for Social Science). The level of significance was established as $\mathrm{p}$ value less than 0.05 . Comparison between quantitative variables was done using Student t-test for parametric data and Mann-Whitney test for non-parametric data to compare two groups. Comparison between qualitative variables was done using Pearson's Chi square test or Fisher's Exact when the cell count $<5 \%$.

Adjustment of the significant covariates was done to detect if DR is an independent predictor of preclinical cardiac ischemia by $\mathrm{Tc}^{99}$ scan using binary logistic regression analysis.

\section{Results}

In our study sample, females were $75 \%(\mathrm{n}=30)$ and males were $25 \%(\mathrm{n}=10)$. The mean age of patients was $62.35 \pm 1.38$ years. The prevalence of DR was $75 \%(n=30)$, positive Tc ${ }^{99}$ scan was seen in $77.5 \%(n=31)$ of patients. The median amount of Albuminuria was 100 (20 - 337.5) mg/24h Table 1. There were no significant differences between patients with DR and those without DR regarding age, sex, duration of DM, type of treatment, DBP, BMI, peripheral neuropathy ( $\mathrm{p}$ value $=0.167,0.401,0.100,0.855,0.071,0.455,0.337$ respectively). There were also no significant differences between patients with DR and those without DR regarding diabetic control (p values of FBS, 2hPP, HB A1c were $0.793,0.420,0.103$ respectively) or lipid profile ( $\mathrm{p}$ values of TC, TG, LDL-C, HDL-C were 0.260, 0.087, 0.813, 0.521 respectively) Table 2.

Patients with DR had statically significant higher SBP (although still within normal range) (126.50 \pm 6.84 vs $120.00 \pm 6.67 \mathrm{mmHg}$ ) and more albuminuria [185 (35 - 362.50) vs $20(20$ - 40) mg/24h] than those without DR ( $\mathrm{p}$ value $0.013,0.001$ ) Table 2 . Concerning cardiac nuclear imaging, the present study showed statistical significant positive association between DR and cardiac ischemia by Tc ${ }^{99}$ scan $(86.7 \%(n=26)$ vs $50.00 \%(n=5)$, $\mathrm{p}$ value $=0.029)$ with lower resting and stress perfusion index in patients with DR $(91.77 \%$ vs $100 \%$; $86.48 \%$ vs $96.27 \%$, p value $=0.008,0.005$ respectively) than those without DR (Table 3). In addition, there was no statis- 
Table 1. Descriptive characteristics of the studied population.

\begin{tabular}{|c|c|}
\hline Variable & Studied population $(\mathrm{n}=40)$ \\
\hline Age & $62.35 \pm 1.38$ \\
\hline Females & $75 \%(\mathrm{n}=30)$ \\
\hline Duration of DM & $11.60 \pm 4.43$ \\
\hline - $\mathrm{OHG}$ & $52.5 \%(n=21)$ \\
\hline - Insulin & $47.5(\mathrm{n}=19)$ \\
\hline SBP mmHg & $124.88 \pm 7.29$ \\
\hline DBP mmHg & $76.05 \pm 4.05$ \\
\hline BMI & $28.36 \pm 1.09$ \\
\hline - $\quad$ Non-advanced $\mathrm{DR}^{*}$ & $22.5 \%(\mathrm{n}=9)$ \\
\hline - $\quad$ Advanced $\mathrm{DR}^{*}$ & $52.5 \%(n=21)$ \\
\hline Peripheral neuropathy & $70 \%(n=28)$ \\
\hline $\mathrm{FBS} \mathrm{mmol} / \mathrm{L}$ & $8.88 \pm 1.50$ \\
\hline 2hPPBS mmol/L & $9.82 \pm 2.43$ \\
\hline HB A1c \% & $9.49 \pm 1.41$ \\
\hline $\mathrm{TC} \mathrm{mmol} / \mathrm{L}$ & $3.5 \pm 0.51$ \\
\hline $\mathrm{TG} \mathrm{mmol} / \mathrm{L}$ & $1.22 \pm 0.32$ \\
\hline LDL-C mmol/L & $2.46 \pm 0.11$ \\
\hline HDL-C mmol/L & $1.81 \pm 0.40$ \\
\hline 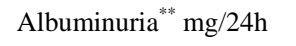 & $100(20-337.5)$ \\
\hline Positive $\mathrm{Tc}^{99}$ scan & $77.5 \%(n=31)$ \\
\hline Resting Perfusion Index & $93.83 \pm 14.01$ \\
\hline Stress Perfusion Index & $88.93 \pm 14.21$ \\
\hline
\end{tabular}

OHG: oral hypoglycemic, SBP: systolic blood pressure, DBP: diastolic blood pressure, FBS: fasting blood sugar, 2hPPBS: 2 hours postprandial blood sugar, HB A1c: hemoglobin A1c, TC: total cholesterol, TG: triglycerides, LDL-C: low density lipoprotein, HDL-C: high density lipoprotein, DR: Diabetic retinopathy. "Non-advanced DR: background and non-proliferative diabetic retinopathy; ${ }^{*}$ Advanced DR: proliferative DR either with or without maculopathy; ${ }^{* *}$ Mann Wittny test was done, median and interquartile range was expressed.

tical significant difference between patients with non-advanced and advanced DR in the risk of CAD ( $\mathrm{p}$ value = 0.815).

Patients with positive $\mathrm{Tc}^{99}$ scan had also statically significant longer T2DM duration (12.19 \pm 4.71 vs $9.56 \pm$ 2.55, p value 0.037), higher SBP and DBP (126.29 \pm 7.30 vs $120.00 \pm 5.00,82.90 \pm 6.93$ vs $75.56 \pm 5.27$, $\mathrm{p}$ value $=$ $0.008,0.006$ ) Table 3. By binary logistic regression, DR was an independent predictor of CAD (Odds ratio was 16.377, 95\% CI was 1.017 - 263.586, p value $=0.049$ ) after adjustment of SBP and albuminuria Table 4.

\section{Discussion}

Understanding the association between DR and systemic vascular diseases is important for the physicians caring for diabetic patients. The presence of DR doesn't only predict the higher risk of cardiovascular disease but also mortality. This association remained even after adjusting for other traditional risk factors [12].

Microvascular dysfunction has been arisen as a significant pathogenic factor in the development of diabetic heart disease [13]. However, there is no simple non-invasive test for the assessment of coronary microcirculation [14]. Medical stress test with SPECT imaging to assess myocardial ischemia has sensitivity $91 \%$ - $96 \%$ and specificity 75\% - 82\% [10] and it is still the best predictor of cardiac events in stable ischemic heart disease [15]. This test has definite advantages over clinical, electrocardiographic, lab and resting echocardiographic data, as it describes the severity and extent of stress-induced myocardial perfusion abnormality [8]. 
Table 2. Comparison between diabetic patients with and without diabetic retinopathy regarding personal characteristics, laboratory investigations and $\mathrm{Tc}^{99}$ scan.

\begin{tabular}{|c|c|c|c|}
\hline \multirow{2}{*}{ Variables } & \multicolumn{3}{|c|}{ Diabetic retinopathy } \\
\hline & Yes $(n=30)$ & No $(n=10)$ & $\mathrm{p}$ value \\
\hline Age & $63.03 \pm 1.24$ & $61.30 \pm 1.54$ & 0.167 \\
\hline Sex (Males) & $30 \%(n=9)$ & $10 \%(\mathrm{n}=1)$ & 0.401 \\
\hline Duration of DM & $12.27 \pm 4.65$ & $9.60 \pm 3.06$ & 0.100 \\
\hline Type of treatment (OHG) & $53.3 \%(n=16)$ & $50.00 \%(\mathrm{n}=5)$ & 0.855 \\
\hline SBP mmHg & $126.50 \pm 6.84$ & $120.00 \pm 6.67$ & 0.013 \\
\hline DBP mmHg & $76.67 \pm 3.46$ & $74.00 \pm 5.16$ & 0.071 \\
\hline BMI & $28.29 \pm 1.07$ & $28.59 \pm 1.19$ & 0.455 \\
\hline Peripheral neuropathy & $73.3 \%(n=22)$ & $60.0 \%(\mathrm{n}=6)$ & 0.337 \\
\hline $\mathrm{FBS} \mathrm{mmol} / \mathrm{L}$ & $8.87 \pm 1.66$ & $8.72 \pm 0.88$ & 0.793 \\
\hline 2hPP mmol/L & $10 \pm 2.16$ & $9.26 \pm 3.18$ & 0.420 \\
\hline HB A1c \% & $8.70 \pm 1.47$ & $8.86 \pm 1.00$ & 0.103 \\
\hline $\mathrm{TC} \mathrm{mmol} / \mathrm{L}$ & $3.57 \pm 0.45$ & $3.34 \pm 0.67$ & 0.260 \\
\hline TG mmol/L & $1.27 \pm 0.33$ & $1.07 \pm 0.21$ & 0.087 \\
\hline LDL-C mmol/L & $2.47 \pm 0.10$ & $2.44 \pm 0.13$ & 0.813 \\
\hline HDL-C mmol/L & $1.81 \pm 0.38$ & $1.88 \pm 0.44$ & 0.521 \\
\hline Albuminuria* mg/24h & $185(35-362.50)$ & $20(20-40)$ & 0.001 \\
\hline Positive $\mathrm{Tc}^{99}$ scan & $86.7 \%(n=26)$ & $50.00 \%(\mathrm{n}=5)$ & 0.029 \\
\hline Resting Perfusion Index & $91.77 \pm 15.71$ & $100.00 \pm 0.00$ & 0.008 \\
\hline Stress Perfusion Index & $77.07 \pm 27.73$ & $93.20 \pm 8.65$ & 0.005 \\
\hline
\end{tabular}

OHG: oral hypoglycemic, SBP: systolic blood pressure, DBP: diastolic blood pressure, FBS: fasting blood sugar, $2 \mathbf{h P P B S : ~} 2$ hours postprandial blood sugar, HB A1c: hemoglobin A1c, TC: total cholesterol, TG: triglycerides, LDL-C: low density lipoprotein, HDL-C: high density lipoprotein. "Mann Wittny test was done, median and interquartile range were expressed.

Generally, the prevalence of silent CAD in diabetic patients is widely varied in literature from $4 \%$ - $70 \%$ [16]. In Greek and Spain population studies on asymptomatic diabetic patients without DR, the prevalence of silent CAD using SPECT were $27.66 \%$ [17] and $13 \%$ [18] respectively while in asymptomatic patients with DR were 75.86\% and 50\% respectively. This difference could be attributed to smaller sample size, longer duration of diabetes, higher fasting and postprandial blood sugar, higher glycosylated hemoglobin and body mass index in our sample compared to the previous studies [17] [18].

In our study, we found that DR is an independent predictor of silent CAD although we excluded all patients with CAD and other traditional risk factors like hypertension, hyperlipidemia and smoking. Our findings are consistent with many clinical studies that diabetic retinopathy is associated with subclinical coronary pathology [4]-[6] [12]-[15]. In a prospective population based study, the authors found that even mild DR is associated with incident CAD independent of other traditional risk factors although this study didn't exclude patients with abnormal lipid profile, high blood pressure, smoking or abnormal creatinine [13]. Another meta-analysis reported that persons with any degree of DR are at higher risk of CAD and all-cause mortality independent of other traditional risk factors [14].

Current evidence suggests that the presence of retinopathy, even in its mildest form, is associated with two- to four folds increase in the risk of CAD and heart failure, independent of cardiovascular risk factors such as smoking, lipid profile, diabetes duration, and glycemic control [6]. This is in agreement with our results which 
Table 3. Comparison between diabetic patients with and without silent CAD regarding personal characteristics, laboratory investigations and $\mathrm{Tc}^{99}$ scan.

\begin{tabular}{|c|c|c|c|}
\hline \multirow{2}{*}{ Variables } & \multicolumn{3}{|c|}{ Silent CAD ( $\mathrm{Tc}^{99}$ scan $)$} \\
\hline & Yes $(n=31)$ & No $(n=9)$ & $\mathrm{p}$ value \\
\hline Age & $63.45 \pm 1.70$ & $63.00 \pm 1.70$ & 0.828 \\
\hline Males & $29.00 \%(\mathrm{n}=9)$ & $11.10 \%(\mathrm{n}=1)$ & 0.404 \\
\hline Females & $71.00 \%(n=22)$ & $88.90 \%(n=8)$ & \\
\hline Duration of DM & $12.19 \pm 4.71$ & $9.56 \pm 2.55$ & 0.037 \\
\hline OHG & $58.10 \%(n=19)$ & $33.33 \%(n=3)$ & 0.265 \\
\hline Insulin & $41.90 \%(n=13)$ & $66.70 \%(\mathrm{n}=6)$ & \\
\hline SBP mmHg & $126.29 \pm 7.30$ & $120.00 \pm 5.00$ & 0.008 \\
\hline DBP mmHg & $76.71 \pm 3.41$ & $73.56 \pm 5.27$ & 0.038 \\
\hline BMI & $28.29 \pm 0.96$ & $28.62 \pm 1.52$ & 0.546 \\
\hline Peripheral neuropathy & $67.70 \%(n=21)$ & $77.80 \%(n=7)$ & 0.697 \\
\hline Retinopathy & $83.87 \%(n=26)$ & $44.44 \%(n=4)$ & 0.029 \\
\hline Non-advanced DR & $30.8 \%(\mathrm{n}=8)$ & $25.0 \%(\mathrm{n}=1)$ & 0.815 \\
\hline Advanced DR & $69.2 \%(n=18)$ & $75.0 \%(\mathrm{n}=3)$ & \\
\hline FBS mmol/L & $9.03 \pm 1.43$ & $8.12 \pm 1.58$ & 0.107 \\
\hline 2hPP mmol/L & $9.97 \pm 2.57$ & $9.26 \pm 1.88$ & 0.451 \\
\hline HB A1c \% & $9.72 \pm 1.34$ & $8.71 \pm 1.43$ & 0.058 \\
\hline $\mathrm{TC} \mathrm{mmol} / \mathrm{L}$ & $3.50 \pm 0.54$ & $3.48 \pm 0.44$ & 0.927 \\
\hline $\mathrm{TG} \mathrm{mmol} / \mathrm{L}$ & $1.22 \pm 0.34$ & $1.23 \pm 0.23$ & 0.936 \\
\hline LDL-C mmol/L & $2.46 \pm 0.12$ & $2.47 \pm 0.11$ & 0.445 \\
\hline HDL-C mmol/L & $1.79 \pm 0.39$ & $1.90 \pm 0.41$ & 0.951 \\
\hline Albuminuria* mg/24h & $100(20-300)$ & $100(20-375)$ & 0.868 \\
\hline Resting Perfusion Index & $92.04 \pm 15.52$ & $100.00 \pm 0.00$ & $<0.001$ \\
\hline Stress Perfusion Index & $85.71 \pm 14.66$ & $100.00 \pm 0.00$ & 0.008 \\
\hline
\end{tabular}

OHG: oral hypoglycemic, SBP: systolic blood pressure, DBP: diastolic blood pressure, FBS: fasting blood sugar, 2hPPBS: 2 hours postprandial blood sugar, HB A1c: hemoglobin A1c, TC: total cholesterol, TG: triglycerides, LDL-C: low density lipoprotein, HDL-C: high density lipoprotein. *Mann Wittny test was done, median and interquartile range were expressed.

Table 4. Logistic regression analysis for independent predictor of cardiac ischemia using $\mathrm{Tc}^{99}$ scan.

\begin{tabular}{cccccc}
\hline Variables & OR & SE & p value & LCI & UCI \\
\hline DR & 16.377 & 1.418 & 0.049 & 1.017 & 263.586 \\
SBP & 1.106 & 0.064 & 0.117 & 0.975 & 1.253 \\
Albuminuria & 0.994 & 0.004 & 0.137 & 0.986 & 1.002 \\
Constant & 0.000 & 7.707 & 0.176 & & \\
\hline
\end{tabular}

SBP: systolic blood pressure, DR: diabetic retinopathy.

found no statistical significant difference between patients with and without advanced retinopathy in the risk of CAD. Despite the widespread interest in studying the link between DR and CAD, the precise underlying pathophysiological mechanism is still uncertain [3]. Studies have shown that diabetic persons with retinopathy are more likely to have myocardial arteriolar abnormalities [19] which affect coronary perfusion and decrease the coronary flow reserve [17] [20]. Moreover, DR has been associated with lower coronary collateral score, higher degrees of coronary calcification [21] leading to more diffuse/severe coronary artery stenosis [22]. These obser- 
vations, in conjunction with ours, support the concept that micro-and macrovascular complications of diabetes share common pathogenic mechanisms beyond other traditional risk factors. Other biochemical pathways can also play a role in this link especially with increased activity of protein kinase $\mathrm{C}$ and glycation of key proteins that lead to formation of advanced glycation end products which predispose to cellular changes, enhanced permeability of retinal vasculature, alterations in retinal blood flow, basement membrane thickening leading to ocular neovascularization [3] [6]. This is support our opinion regarding the fundamental role of proper screening and diagnosis of CAD for the prevention and early treatment of coronary events.

Although many epidemiological studies didn't find hypertension as a consistent risk factor for DR incidence and progression, but at the same time, many randomized control trials showed that a decrease in systolic blood pressure by $10 \mathrm{mmHg}$ associated with parallel decrease in the risk of retinopathy progression by $35 \%$ and vision loss by 50\% [5]. This is conceded with our results which revealed that patients with DR had statically significant higher SBP (although still within normal range) than patients without DR.

Many experimental studies found a high correlation between pathological changes in the retinal and renal vasculature [23] [24]. Epidemiological studies have constantly demonstrated that diabetic retinopathy is associated with microalbuminuria and clinical nephropathy, independent of hypertension and other shared risk factors [25]-[27]. This is in agreement with our results which found patients with DR had statically significant more albuminuria than those without DR. Even with the abundant evidence that DR is associated with a range of systemic vascular complications but still there is incomplete understanding of the pathogenesis of DR itself [28].

\section{Conclusion}

DR is an independent predictor of asymptomatic CAD even with normal stress ECG and echocardiography. Routine screening for CAD using $\mathrm{TC}^{99}$ scan is recommended in patients with DR even if asymptomatic. Systolic blood pressure decreases even if normal is associated with less prevalence of DR. More multi-centric prospective studies are needed to elucidate the effect of the degree of DR on CAD risk that may have great impact on formulation of CAD screening guidelines in diabetic patients.

\section{Acknowledgements}

The authors have no financial interests or any other kind of conflicts or disclosure related to the material in the manuscript to report. There is no compliance with any research funding agency.

\section{References}

[1] Keenan, H.A., Costacou, T., Sun, J.K., Doria, A., Cavellerano, J., Coney, J., Orchard, T.J., Aiello, L.P. and King, G.I. (2007) Clinical Factors Associated With Resistance to Microvascular Complications in Diabetic Patients of Extreme Disease Duration. The 50-Year Medalist Study. Diabetes Care, 30, 1995-1997. http://dx.doi.org/10.2337/dc06-2222

[2] Hogan, P., Dall, T. and Nikolov, P. (2003) Economic Costs of Diabetes in the Us in 2002. Diabetes Care, 26, 917-932. http://dx.doi.org/10.2337/diacare.26.3.917

[3] Cheung, N., Liewb, G. and Wonga, T.Y. (2010) Current Approaches to Retinopathy as a Predictor of Cardiovascular Risk. In: Hammes, H.-P. and Porta, M., Eds., Experimental Approaches to Diabetic Retinopathy, Vol. 20, Front Diabetes, Karger, Basel, 203-219.

[4] Cheung, N. and Wong, T.Y. (2007) Diabetic Retinopathy and Systemic Vascular Complications. Progress in Retinal and Eye Research, 27, 161-176. http://dx.doi.org/10.1016/j.preteyeres.2007.12.001

[5] Cheung, N., Mitchell, P. and Wong, T.Y. (2010) Diabetic Retinopathy. Lancet, 376, 124-136. http://dx.doi.org/10.1016/S0140-6736(09)62124-3

[6] Cheung, N., Wang, J.J., Rogers, S.L., Brancati, F., Klein, R., Sharrett, A.R. and Wong, T.Y., ARIC (Atherosclerosis Risk in Communities) Study Investigators (2008) Diabetic Retinopathy and Risk of Heart Failure. Journal of the American College of Cardiology, 51, 1573-1578. http://dx.doi.org/10.1016/j.jacc.2007.11.076

[7] American Academy of Ophthalmology (2003) Preferred Practice Pattern. Diabetic Retinopathy 2003. Calif, San Francisco.

[8] Scholte, A., Schuijf, J., Kharagjitsingh, A., Dibbets-Schneider, P., Stokkel, M., Van Der Wall, E., et al. (2009) Prevalence and Predictors of an Abnormal L Stress Myocardial Perfusion Study in Asymptomatic Patients with Type 2 Diabetes Mellitus. European Journal of Nuclear Medicine and Molecular Imaging, 36, 567-575.

http://dx.doi.org/10.1007/s00259-008-0967-y 
[9] Underwood, S.R., Anagnostopoulos, C., Cerqueira, M., Ell, P.J., Flint, E.J., Harbinson, M., et al. (2004) Myocardial Perfusion Scintigraphy: The Evidence. A Consensus Conference Organized by the British Cardiac Society, the British Nuclear Cardiology Society and the British Nuclear Medicine Society, Endorsed by the Royal College of Physicians of London and the Royal College of Radiologists. European Journal of Nuclear Medicine and Molecular Imaging, 31, 261-291. http://dx.doi.org/10.1007/s00259-003-1344-5

[10] Roelker, E. (2008) Screening for Coronary Artery Disease in Patients with Diabetes. Diabetes Spectrum, 21, $166-171$. http://dx.doi.org/10.2337/diaspect.21.3.166

[11] Fricke, E., Fricke, H., Weise, R., Kammeier, A., Hagedorn, R., Lotz, N., Lindner, O., Tschoepe, D. and Burchert, W. (2005) Attenuation Correction of Myocardial SPECT Perfusion Images with Low-Dose CT: Evaluation of the Method by Comparison with Perfusion Pet. Journal of Nuclear Medicine, 46, 736-744.

[12] Fuller, J.H., Stevens, L.K. and Wang, S.L., the WHO Multinational Study Group (2001) Risk Factors for Cardiovascular Mortality and Morbidity: The WHO Multinational Study of Vascular Disease in Diabetes. Diabetologia, 44, S54S64. http://dx.doi.org/10.1007/PL00002940

[13] Kawasaki, R., Tanaka, S., Sone, H., Yokote, K., Ishibashi, S., Katayama, S., et al. (2013) Risk of Cardiovascular Diseases Is Increased Even with Mild Diabetic Retinopathy. The Japan Diabetes Complications Study. Ophthalmology, 120, 574-582. http://dx.doi.org/10.1016/j.ophtha.2012.08.029

[14] Kramer, C.K., Rodrigues, T.C., Canani, L.H., Gross, J.L. and Azevedo, M.J. (2011) Diabetic Retinopathy Predicts All-Cause Mortality and Cardiovascular Events in both Type 1 and 2 Diabetes. Meta-Analysis of Observational Studies. Diabetes Care, 34, 1238-1244. http://dx.doi.org/10.2337/dc11-0079

[15] Gimelli, A., Rossi, G., Landi, P., Marzullo, P., Iervasi, G., L’Abbate, A. and Rovai, D. (2009) Stress/Rest Myocardial Perfusion Abnormalities by Gated SPECT: Still the Best Predictor of Cardiac Events in Stable Ischemic Heart Disease. Journal of Nuclear Medicine, 50, 546-553. http://dx.doi.org/10.2967/jnumed.108.055954

[16] Albers, A.R., Krichavsky, M.Z. and Balady, G.J. (2006) Stress Testing in Patients with Diabetes Mellitus: Diagnostic and Prognostic Value. Circulation, 113, 583-592. http://dx.doi.org/10.1161/CIRCULATIONAHA.105.584524

[17] Ioannidis, G.L., Peppa, M., Rontogianni, P., Callifronas, M., Papadimitriou, C., Chrysanthopoulou, G., Anthopoulos, L., Kesse, M. and Thalassinos, N. (2004) The Concurrence of Microalbuminuria and Retinopathy with Cardiovascular Risk Factors; Reliable Predictors of Asymptomatic Coronary Artery Disease in Type 2 Diabetes. Hormones (Athens), 3, 198-203. http://dx.doi.org/10.14310/horm.2002.11127

[18] Hernández, C.L., Candell-Riera, J., Ciudin, A., Francisco, G., Aguadé-Bruix, S. and Simó, R. (2011) Prevalence and Risk Factors Accounting for True Silent Myocardial Ischemia: A Pilot Case-Control Study Comparing Type 2 Diabetic with Non-Diabetic Control Subjects. Cardiovascular Diabetology, 10, 9.

[19] Factor, S.M., Okun, E.M. and Minase, T. (1980) Capillary Microaneurysms in the Human Diabetic Heart. New England Journal of Medicine, 302, 384-388. http://dx.doi.org/10.1056/NEJM198002143020706

[20] Giugliano, D., Acampora, R., De Rosa, N., Quatraro, A., De Angelis, L., Ceriello, A. and D’Onofrio, F. (1993) Coronary Artery Disease in Type-2 Diabetes Mellitus: A Scintigraphic Study. Diabete \& Metabolisme, 19, 463-466.

[21] Celik, T., Berdan, M.E., Iyisoy, A., Kursaklioglu, H., Turhan, H., Kilic, S., Gulec, M., Ozturk, S. and Isik, E. (2005) Impaired Coronary Collateral Vessel Development in Patients with Proliferative Diabetic Retinopathy. Clinical Cardiology, 28, 384-388. http://dx.doi.org/10.1002/clc.4960280808

[22] Norgaz, T., Hobikoglu, G., Aksu, H., Guveli, A., Aksoy, S., Ozer, O., Bolca, O. and Narin, A. (2005) Retinopathy Is Related to the Angiographically Detected Severity and Extent of Coronary Artery Disease in Patients with Type 2 Diabetes Mellitus. International Heart Journal, 46, 639-646. http://dx.doi.org/10.1536/ihj.46.639

[23] Chavers, B.M., Mauer, S.M., Ramsay, R.C. and Steffes, M.W. (1994) Relationship between Retinal and Glomerular Lesions in IDDM Patients. Diabetes, 43, 441-446. http://dx.doi.org/10.2337/diab.43.3.441

[24] Nag, S., Robertson, D.M. and Dinsdale, H.B. (1980) Morphological Changes in Spontaneously Hypertensive Rats. Acta Neuropathologica, 52, 27-34. http://dx.doi.org/10.1007/BF00687225

[25] Cruickshanks, K.J., Ritter, L.L., Klein, R. and Moss, S.E. (1993) The Association of Microalbuminuria with Diabetic Retinopathy. The Wisconsin Epidemiologic Study of Diabetic Retinopathy. Ophthalmology, 100, 862-867. http://dx.doi.org/10.1016/S0161-6420(93)31562-9

[26] Edwards, M.S., Wilson, D.B., Craven, T.E., Stafford, J., Fried, L.F., Wong, T.Y., Klein, R., Burke, G.L. and Hansen, K.J. (2005) Associations between Retinal Microvascular Abnormalities and Declining Renal Function in the Elderly Population: The Cardiovascular Health Study. American Journal of Kidney Diseases, 46, 214-224. http://dx.doi.org/10.1053/j.ajkd.2005.05.005

[27] Klein, R., Klein, B.E., Moss, S.E. and Cruickshanks, K.J. (1995) Ten-Year Incidence of Gross Proteinuria in People with Diabetes. Diabetes, 44, 916-923. http://dx.doi.org/10.2337/diab.44.8.916

[28] Frank, R.N. (2004) Diabetic Retinopathy. New England Journal of Medicine, 350, 48-58. http://dx.doi.org/10.1056/NEJMra021678 
Scientific Research Publishing (SCIRP) is one of the largest Open Access journal publishers. It is currently publishing more than 200 open access, online, peer-reviewed journals covering a wide range of academic disciplines. SCIRP serves the worldwide academic communities and contributes to the progress and application of science with its publication.

Other selected journals from SCIRP are listed as below. Submit your manuscript to us via either submit@scirp.org or Online Submission Portal.
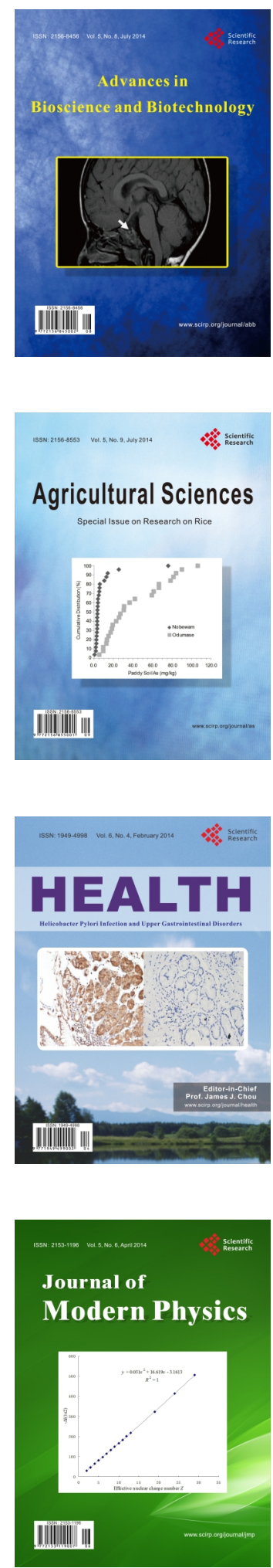
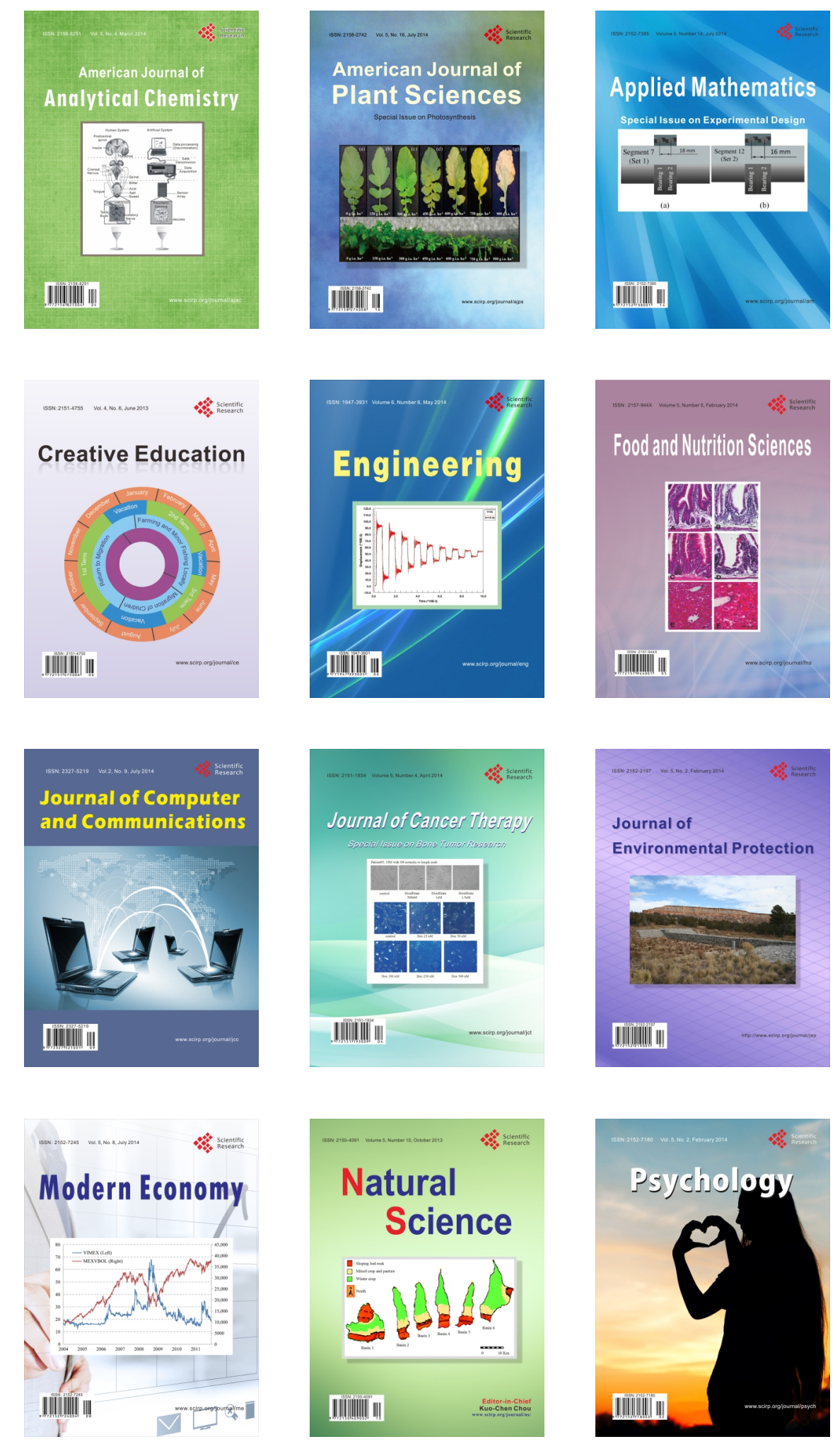